\title{
Effects of preweaning nutritional deprivation on basal metabolism and thermoregulatory thermogenesis in the rat
}

\author{
By D. V. MURALIDHARA AND P. S. SHETTY* \\ Nutrition Research Centre (ICMR), Department of Physiology, St. John's Medical \\ College, Bangalore 560 034, India
}

(Received 10 March 1986 - Accepted 10 June 1986)

1. Nutritional deprivation was induced preweaning in Wistar rats by increasing the litter size to sixteen, while paired litters with only five pups served as controls. The nutritionally deprived pups were rehabilitated after weaning by ad lib. access to an adequate diet.

2. The body-weights and body lengths were significantly lower in the nutritionally deprived group and significant differences persisted even after 9 weeks of rehabilitation.

3. The body temperature of the nutritionally deprived animals was significantly lower than that of their paired controls, both before and following nutritional rehabilitation, except for a short period after weaning when the nutritionally deprived animals were initially given the diet ad lib.

4. The resting oxygen consumption of the nutritionally deprived animals was comparable to that of the controls when corrected for metabolic body size, both before and after weaning. Noradrenaline-stimulated increase in $\mathrm{O}_{2}$ consumption (non-shivering thermogenesis; NST) was reduced by $50 \%$ at weaning in the nutritionally deprived animals and returned to levels comparable to those of controls within a short period of rehabilitation.

5. The decrease in NST capacity seen in the nutritionally deprived animals was associated with an inability to thermoregulate when exposed to cold $\left(5^{\circ}\right)$, resulting in death. Cold-induced thermogenesis (CIT) also reappeared soon after nutritional rehabilitation.

6. Reduction in metabolic rate, NST and CIT seen in the animals nutritionally deprived preweaning was short-lived and disappeared soon after nutritional rehabilitation. Rapid reversal of these physiological changes indicates that they do not confer any long-term benefit or change in metabolic efficiency and are unlike the changes in body size and growth which do not completely recover following nutritional rehabilitation.

Reduction in energy intake results in changes in body size and body composition, as well as a reduction in energy output, in order to maintain energy homeostasis (Grande, 1964; Forsum et al. 1981). The effects of early nutritional deprivation of the rat, before weaning, on body size and on other anthropometric indices have been reported (Widdowson \& McCance, 1960). It is also well documented that adequate nutritional rehabilitation of rats nutritionally deprived preweaning does not permit complete 'catch-up' growth, unlike that seen in rats undernourished and rehabilitated after weaning (McCance, 1976).

Restricted energy intakes lead to a reduction in energy output; the reduced output may appear as a reduced metabolic rate, reduced regulatory thermogenesis and possibly a reduction in the extent of, or even the cost of, physical activity. Reduction in metabolic rate is well-known following prolonged periods of restricted energy intake (Mitchell, 1962) and this change is largely attributable to changes in body composition, chiefly the lean tissue content (Grande, 1964). Variations in regulatory thermogenesis, such as non-shivering thermogenesis (NST), may also be important and a reduced NST capacity is associated with a defect in cold-induced thermogenesis (CIT), as seen in genetically obese strains $(o b / o b$ mice), resulting in the inability to maintain core temperature when exposed to a cold environment for reasonable periods of time (Davis \& Mayer, 1954; Trayhurn \& James, 1978),

The present study was designed to look at changes in basal oxygen consumption, noradrenaline-stimulated increase in $\mathrm{O}_{2}$ consumption and tolerance to cold exposure in

* For reprints. 
Wistar rats which were nutritionally deprived preweaning by increasing their litter size. It was also designed to determine whether adequate nutritional rehabilitation reverses these processes, which were aimed at reducing the energy output of the animal, and whether any residual change in metabolic efficiency could be detected.

\section{MATERIALS AND METHODS}

Inbred female Wistar rats were mated to litter in pairs. Litters of half the dams were nutritionally deprived during the preweaning period by increasing the litter size to sixteen, while the other paired litter, with the number of pups reduced to five, served as controls (Widdowson \& McCance, 1960). Both the control and preweaning nutritionally deprived (PND) pups were housed with their dams at $25 \pm 2^{\circ}$ in polypropylene cages. Food (standard rat pellet diet, energy $15 \mathrm{~kJ} / \mathrm{g}$, protein $200 \mathrm{~g} / \mathrm{kg}$; Hindustan Lever, Bombay) and water were available $a d l i b$. to all lactating mothers. For $21 \mathrm{~d}$ post-partum, i.e. the period before complete weaning, body temperatures (oral) of all pups were recorded twice weekly at 09.00 and 18.00 hours, using a digital thermometer. The temperature probe was introduced into the oral cavity and the jaws held together gently to prevent any sucking or chewing on the probe. Body-weight (accuracy to within $0 \cdot 1 \mathrm{~g}$ ), body length (nose-anus), and tail length (accuracy to within $1 \mathrm{~mm}$ ) were measured twice weekly.

On day $20 \pm 1$ after birth, the resting metabolic rate (RMR) of the pups was determined in groups of four or five at thermoneutrality $\left(30 \pm 1^{\circ}\right)$ using a closed-circuit $\mathrm{O}_{2}$ consumption system (Muralidhara \& Shetty, 1983). The system consisted of an air-tight chamber for the animal and the pressure inside the chamber was raised above the ambient pressure by delivering a predetermined volume of $\mathrm{O}_{2}$. Expired $\mathrm{CO}_{2}$ and $\mathrm{H}_{2} \mathrm{O}$ were absorbed by an absorbent. The time taken for the chamber pressure to return to its initial level, which was determined by use of a light-sensitive device attached to a sensitive manometer, provided the rate of utilization of $\mathrm{O}_{2}$ by the animal. After the determination of baseline resting $\mathrm{O}_{2}$ consumption, the capacity for NST was assessed by measuring the increase in $\mathrm{O}_{2}$ consumption over $2 \mathrm{~h}$ following a subcutaneous injection of noradrenaline $(250 \mu \mathrm{g} / \mathrm{kg})$. Dose-reponse studies carried out earlier in both control and PND rats had shown that maximal response was obtained at this dose of noradrenaline. Measurements of $\mathrm{O}_{2}$ consumption carried out on any day included measurements made for equal numbers of both control and PND animals. At weaning (about day 21), pups from both groups were individually exposed to cold $\left(5^{\circ}\right)$ for $2 \mathrm{~h}$ and the changes in oral temperature were monitored at half-hourly intervals to assess CIT.

Both the control and PND animals were given free access to food (standard rat pellet diet) and water at weaning and the animals which were nutritionally deprived during the preweaning period were thus rehabilitated. The housing conditions were similar to those described for the first part of the study and each cage accommodated four to five rats. The indices studied earlier were measured at periodic intervals till the animals were 12-14 weeks old (i.e. approximately 10 weeks of rehabilitation). Measurements of body-weight, body length and tail length were recorded only once weekly. During the postweaning period, rectal temperature was measured since the thermometer probe could easily be inserted into the rectum of the animal. The temperature was recorded both in the morning and in the evening once weekly. The RMR and NST capacities of each animal were assessed individually, during the postweaning period, within $10 \mathrm{~d}$ of weaning and subsequently at 8-10 weeks of age and then when the animals were 12-14 weeks old, i.e. following 6 and 10 weeks of rehabilitation, respectively. During the measurement of $\mathrm{O}_{2}$ consumption both in the pre- and postweaning period, the animals were partially restrained and were given sufficient time (usually $20-30 \mathrm{~min}$ ) to adjust to the conditions inside the respiration 
chamber. The results of the RMR and NST based on $\mathrm{O}_{2}$ consumption measurements were expressed after conversion to standard temperature and pressure, dry, as $\mathrm{ml} / \mathrm{h}$ per animal, $\mathrm{ml} / \mathrm{h}$ per $\mathrm{kg}$ body-weight and $\mathrm{ml} / \mathrm{min}$ per $\mathrm{kg}$ metabolic body size (body-weight ${ }^{0 \cdot 75}$ ). Change in body temperature following cold exposure $\left(5^{\circ}\right)$ for $2 \mathrm{~h}$ was also monitored during this period in each animal at 4,8 and 12 weeks of age.

\section{Statistics}

All values are presented as means with their standard errors. Statistical significance of differences between groups was determined using Student's unpaired $t$ test, all values with $P<0.05$ being considered as statistically significant.

\section{RESULTS}

\section{Anthropometric values}

The body-weight, body length and tail length of the PND rats were significantly lower than those of the control group throughout the preweaning period. These differences appeared as early as day 3 after birth (Table 1). In both sexes, the differences in body-weight and body length persisted even after 9 weeks of nutritional rehabilitation. However, significant differences in tail lengths of both sexes were seen only up to 4 weeks of rehabilitation.

\section{Body temperature}

During the preweaning period the oral temperature of PND rats was significantly lower than that of the controls. The differences were noticed from the 3rd day after birth and at weaning the oral temperature of the PND pups was $34 \cdot 2$ (SE 0.3$)^{\circ}$ while that of the controls was $35.4(\mathrm{SE} 0.8)^{\circ}(P<0.001)$. During the early period of nutritional rehabilitation the PND pups showed a striking increase in the rectal temperature, and after 2 weeks of rehabilitation the differences between the two groups seen at weaning disappeared (PND rats $36.3(\mathrm{SE} 0 \cdot 2)^{\circ}$, controls $36.2(\mathrm{SE} 0 \cdot 2)^{\circ}$. Differences, however, reappeared during the subsequent weeks and at 12 weeks of age, the rectal temperature of controls was $37.0(\mathrm{SE} 0.1)^{\circ}$ while that of the PND rats was significantly lower at $36.4(\mathrm{SE} 0.2)^{\circ}$ $(P<0.001)$. The diurnal rhythm in body temperature was always seen even in the nutritionally deprived animals, during both pre- and postweaning periods.

\section{Resting $\mathrm{O}_{2}$ consumption and NST capacity}

The resting $\mathrm{O}_{2}$ consumption determined at weaning (day 21), $32 \mathrm{~d}$, at 9 and 12 weeks of age and corrected for body-weight ${ }^{\cdot \cdot 75}$ are represented in Fig. 1, while the total $\mathrm{O}_{2}$ consumption expressed per animal and per unit body-weight at 21 and $32 \mathrm{~d}$ of age and at 9 and 12 weeks of age are summarized in Table 2. There were no sex differences in the RMR of the two groups at weaning although differences between the sexes were evident subsequently. The NST capacity, represented as an increase in $\mathrm{O}_{2}$ consumption over RMR following the administration of noradrenaline, also measured at the same intervals of time and corrected for body-weight $t^{0.75}$, showed differences only at the time of weaning (Fig. 1). The absolute capacity for NST per animal was $50 \%$ lower at weaning in the nutritionally deprived group. At 8 and 12 weeks of age the absolute NST capacity $(\mathrm{ml} / \mathrm{h}$ per animal) of the female PND pups alone appeared to be significantly lower than that of their own controls.

\section{Response to cold exposure $\left(5^{\circ}\right)$}

Exposure to cold $\left(5^{\circ}\right)$ at $21 \mathrm{~d}$ of age resulted in the death of PND pups between 60 and $90 \mathrm{~min}$ after exposure, indicating their inability to thermoregulate and maintain body 
Table 1. Anthropometric values of preweaning nutritionally deprived $(P N D)$ rat pups and controls $(C)$, before and after weaning.

(Mean values with their standard errors)

\begin{tabular}{|c|c|c|c|c|c|c|c|c|c|}
\hline \multirow[b]{2}{*}{ Age } & \multirow[b]{2}{*}{ Sex } & \multirow[b]{2}{*}{ Group } & \multirow[b]{2}{*}{$n$} & \multicolumn{2}{|c|}{ Body-wt (g) } & \multicolumn{2}{|c|}{ Body length $(\mathrm{mm})$} & \multicolumn{2}{|c|}{ Tail length (mm) } \\
\hline & & & & Mean & SEM & Mean & SEM & Mean & SEM \\
\hline \multicolumn{10}{|c|}{ Preweaning (d) } \\
\hline 3 & $3+q$ & $\begin{array}{c}\mathrm{C} \\
\text { PND }\end{array}$ & $\begin{array}{l}20 \\
32\end{array}$ & $\begin{array}{l}10 \\
8^{* * *}\end{array}$ & $\begin{array}{l}0.7 \\
0.3\end{array}$ & $\begin{array}{l}73 \\
67^{* *}\end{array}$ & $\begin{array}{l}1 \cdot 6 \\
0.8\end{array}$ & $\begin{array}{l}27 \\
24 * *\end{array}$ & $\begin{array}{l}0.9 \\
0.5\end{array}$ \\
\hline 15 & $a+q$ & $\begin{array}{c}\mathrm{C} \\
\text { PND }\end{array}$ & $\begin{array}{l}20 \\
32\end{array}$ & $\begin{array}{l}27 \\
15^{* * *}\end{array}$ & $\begin{array}{l}0 \cdot 8 \\
0 \cdot 3\end{array}$ & $\begin{array}{l}105 \\
89^{* * *}\end{array}$ & $\begin{array}{l}1 \cdot 2 \\
0 \cdot 7\end{array}$ & $\begin{array}{l}54 \\
45^{* * *}\end{array}$ & $\begin{array}{l}1 \cdot 8 \\
0 \cdot 8\end{array}$ \\
\hline 21 & $0+q$ & $\stackrel{\mathrm{C}}{\mathrm{PND}}$ & $\begin{array}{l}10 \\
16\end{array}$ & $\begin{array}{l}46 \\
23^{* * *}\end{array}$ & $\begin{array}{l}1 \cdot 1 \\
0 \cdot 7\end{array}$ & $\begin{array}{l}131 \\
106^{* * *}\end{array}$ & $\begin{array}{l}1 \cdot 4 \\
1 \cdot 2\end{array}$ & $\begin{array}{l}79 \\
64^{* * * *}\end{array}$ & $\begin{array}{l}2 \cdot 2 \\
1 \cdot 1\end{array}$ \\
\hline \multicolumn{10}{|c|}{$\begin{array}{l}\text { Postweaning } \dagger \\
\text { (weeks) }\end{array}$} \\
\hline 8 & 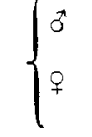 & $\begin{array}{c}\text { C } \\
\text { PND } \\
\text { C } \\
\text { PND }\end{array}$ & $\begin{array}{l}10 \\
13 \\
10 \\
15\end{array}$ & $\begin{array}{l}145 \\
114^{* * *} \\
126 \\
103^{* *}\end{array}$ & $\begin{array}{l}6 \cdot 0 \\
4 \cdot 3 \\
6 \cdot 2 \\
3 \cdot 2\end{array}$ & $\begin{array}{l}191 \\
182^{* * *} \\
183 \\
173^{* * *}\end{array}$ & $\begin{array}{l}1.2 \\
1.5 \\
1.5 \\
1.6\end{array}$ & $\begin{array}{l}156 \\
146 \\
149 \\
143\end{array}$ & $\begin{array}{l}4 \cdot 4 \\
3 \cdot 5 \\
2 \cdot 0 \\
2 \cdot 9\end{array}$ \\
\hline 10 &  & $\begin{array}{c}\text { C } \\
\text { PND } \\
\text { C } \\
\text { PND }\end{array}$ & $\begin{array}{l}10 \\
13 \\
10 \\
15\end{array}$ & $\begin{array}{l}180 \\
152^{*} \\
151 \\
123^{* * *}\end{array}$ & $\begin{array}{l}8 \cdot 2 \\
5 \cdot 8 \\
5 \cdot 4 \\
2 \cdot 6\end{array}$ & $\begin{array}{l}211 \\
205^{*} \\
196 \\
189^{* *}\end{array}$ & $\begin{array}{l}2 \cdot 1 \\
5 \cdot 1 \\
1.6 \\
1.2\end{array}$ & $\begin{array}{l}176 \\
169 \\
164 \\
158\end{array}$ & $\begin{array}{l}5 \cdot 4 \\
0 \cdot 3 \\
2 \cdot 0 \\
2 \cdot 8\end{array}$ \\
\hline 12 & 0 & $\begin{array}{c}\text { C } \\
\text { PND } \\
\text { C } \\
\text { PND }\end{array}$ & $\begin{array}{l}10 \\
13 \\
10 \\
15\end{array}$ & $\begin{array}{l}217 \\
192^{*} \\
166 \\
141^{* * * *}\end{array}$ & $\begin{array}{l}8 \cdot 3 \\
5 \cdot 1 \\
4 \cdot 2 \\
2 \cdot 4\end{array}$ & $\begin{array}{l}221 \\
216^{*} \\
201 \\
196^{*}\end{array}$ & $\begin{array}{l}1 \cdot 5 \\
9 \cdot 4 \\
2 \cdot 0 \\
1 \cdot 4\end{array}$ & $\begin{array}{l}183 \\
178 \\
168 \\
166\end{array}$ & $\begin{array}{l}5 \cdot 2 \\
2 \cdot 8 \\
1 \cdot 7 \\
2 \cdot 0\end{array}$ \\
\hline
\end{tabular}

${ }^{*} P<0.05,{ }^{* *} P<0.01,{ }^{* * *} P<0.001$.

$\dagger$ Period of nutritional rehabilitation for PND animals.

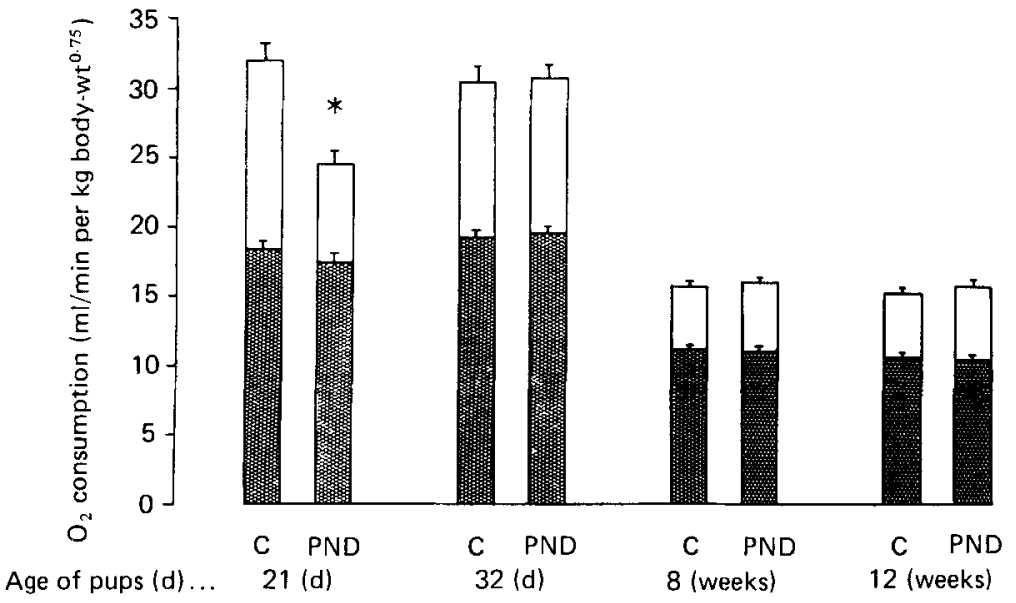

Fig. 1. Oxygen consumption corrected for metabolic body size (body-weight ${ }^{0.75}$ ) before (霜) and after ( $\square$ ) injection of noradrenaline $(250 \mu \mathrm{g} / \mathrm{kg})$ into preweaning nutritionally deprived (PND) rat pups $(n 23)$ and controls (C) ( $n$ 19) at various intervals after weaning (animals weaned at about $21 \mathrm{~d}$ of age). Values are means, with their standard errors represented by vertical bars. ${ }^{*} P<0.001$. 
Thermogenesis and nutritional deprivation





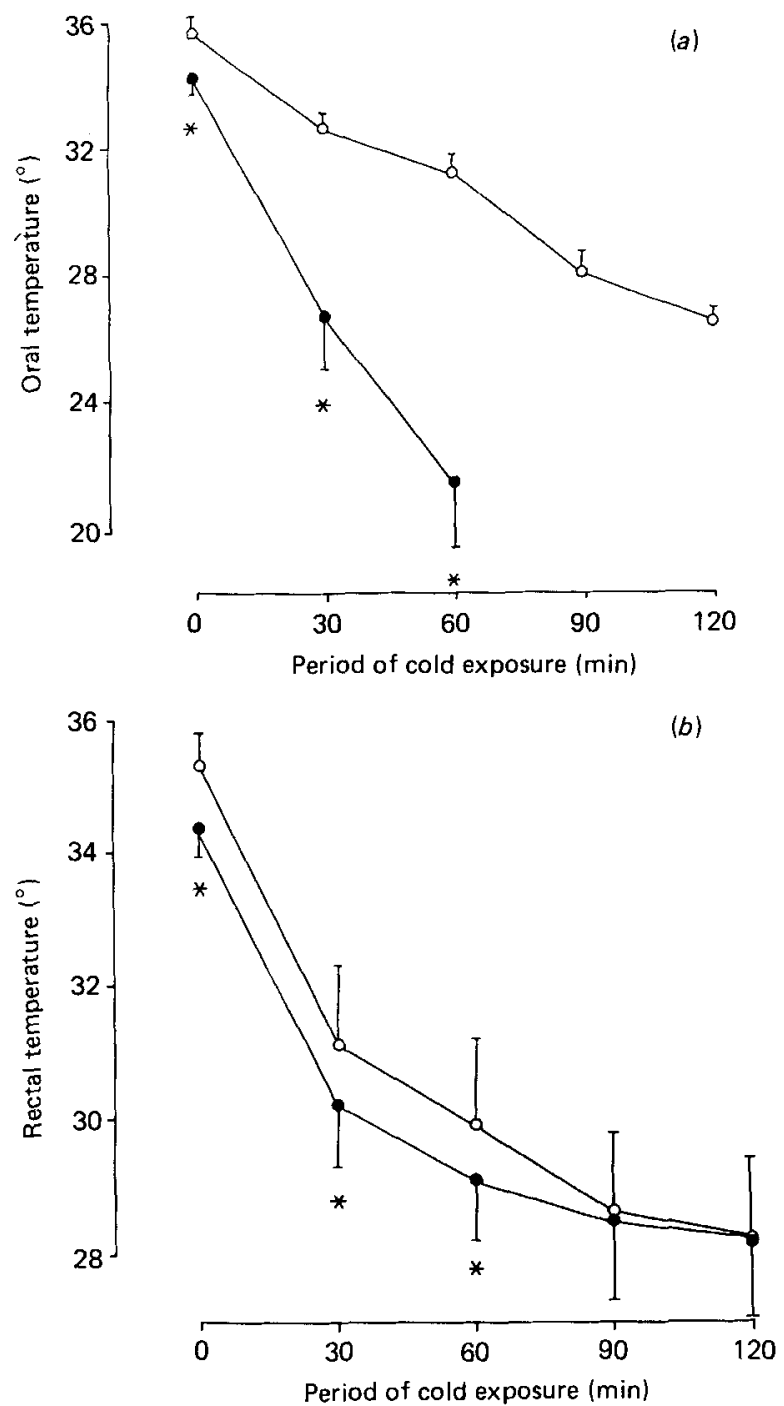

Fig. 2. Changes in body temperature of rat pups during cold exposure ( $5^{\circ}$ ) for $2 \mathrm{~h}$. (a) Oral temperatures of 21-d-old pups; values are means and $1 \mathrm{sD}$, represented by vertical bars, for eight preweaning nutritionally deprived (PND) pups $(O)$ compared with five controls $(O)$. (b) Rectal temperatures of 30-d-old pups; values are means and 1 sD represented by vertical bars of thirty-two PND pups (O) compared with twenty controls $(O) .{ }^{*} P<0.01$.

temperature (Fig. $2 a$ ). At the end of cold exposure for $60 \mathrm{~min}$ the body temperature (oral) of controls was $31.2(\mathrm{SE} 0.3)^{\circ}$ and that of the PND pups was $21.4(\mathrm{SE} 0.7)^{\circ}(P<0.001)$. At 4 weeks of age the fall in core temperature on cold exposure in the PND rats (Fig. $2 b$ ) was significantly greater than that of their controls during the 1st hour, particularly in the females. During the 2nd hour, however, the core temperatures of all the PND rats were comparable to those of the control animals. This small difference in cold tolerance between the two groups seen during the 1 st hour of cold exposure was not apparent at 8 and 12 weeks of age when exposure to cold was repeated, indicating that the PND rats were capable of thermoregulation after adequate nutritional rehabilitation. 


\section{DISCUSSION}

Changes in growth rate and body composition of nutritionally deprived animals have been reported earlier (Apfelbaum, 1978; Forsum et al. 1981) and the morphometric changes (in body-weight, body length and tail length) seen in the PND animals in the present study were similar to those in earlier reports on the effects of nutritional deprivation by alteration of litter size (Widdowson \& McCance, 1960). Widdowson \& McCance (1960) have reported a two- to four-fold difference in the weight of animals from large litters on day 21 and have also demonstrated that the growth rate after free access to food is slower in these small rats from large litters, a feature seen in the present study too.

A decrease in core temperature was seen in the PND pups preweaning in the present study and has also been reported in severe protein and energy restriction in humans (Brenton et al. 1967) and animals (McCance \& Mount, 1960). Low core temperature is also seen in genetic mutants such as the obese $(o b / o b)$ mouse and the diabetic $(d b / d b)$ mouse (Trayhurn \& James, 1978; Trayhurn, 1979), and the reduced set-point for body temperature in these mutants suggests a reduced need for energy expenditure on thermoregulatory thermogenesis. During the early phase of nutritional rehabilitation after weaning, when the PND pups had access to food, the differences in body temperature disappeared. McCance \& Mount (1960) have also reported restoration of body temperature of pigs rehabilitated after dietary restriction. It is likely that this increase in body temperature is the result of increased dietary thermogenesis associated with a rapid increase in protein synthesis, similar to that seen in malnourished children with kwashiorkor during rehabilitation (Ashworth, 1969). However, differences in core temperature reappeared between the control pups and the rehabilitated pups which persisted up to the time the PND pups were 12-14 weeks old. It would appear that the hypothalamic set-point for body temperature is preset at a lower level as a result of the early nutritional deprivation during the suckling period (Dorner, 1974). Despite the decrease in body temperature, the diurnal rhythm seemed to persist in the PND rats, albeit at a lower level, and was identical in phase and amplitude. A similar feature is also seen in the genetically obese and the diabetic obese mouse (Trayhurn, 1979).

Adaptive changes in the energy output during or following dietary restrictions are also expected to occur, as seen in changes in metabolic rate, dietary thermogenesis, thermoregulatory thermogenesis and activity (Trayhurn \& James, 1981). Reduction in RMR is an important accompaniment of any form of energy restriction in animals (Khan \& Bender, 1979, Viteri \& Totun, 1980) and man (Apfelbaum, 1978; Shetty et al. 1979) and, at weaning, the PND rats in the present study showed a depression in total resting $\mathrm{O}_{2}$ consumption. This decrease in absolute RMR appears to be largely attributable to a reduction in body-weight since the absolute RMR of the PND pups on day 20 was comparable to the RMR of normal weanling rats of equivalent body-weight which were only $17 \mathrm{~d}$ old (Kibler $\&$ Brody, 1942). This is further supported by the differences that emerged when RMR was corrected for body-weight ${ }^{0.75}$, an expression that is said to detect the presence of differences in metabolic efficiency, if any, between groups (Kleiber, 1947). These differences in RMR per se in the PND pups corresponded to differences in body-weight between the two groups. The $\mathrm{O}_{2}$ consumption of the PND rats was significantly increased when expressed per $\mathrm{kg}$ body-weight possibly because the contribution to body-weight from metabolically less active adipose tissue is minimal in PND rats. Previous reports on carcass analysis of rats of $2 \mathrm{~d}$ of age, where the size of the litters was altered, have shown that the percentage lean tissue or protein content is not altered despite wide and significant differences in body-weight of pups of litter size four or eight as compared with pups reared sixteen per litter, while the percentage lipid is significantly reduced as the litter size increases (Wurtman \& Miller, 1976). Nutritional rehabilitation post-weaning seemed to alter the relation between RMR 
and body composition. At 9 weeks of age, the absolute RMR continued to remain low in the PND rats, as did their body-weights; thus RMR, expressed per unit body-weight was no longer significantly different at this age. This may have been a result of excess deposition of adipose tissue, a feature which is supported by carcass analysis done at about the same age, i.e. $58 \mathrm{~d}$ of age (Wurtman \& Miller, 1976). At 12 weeks of age the absolute RMR also attained values similar to that of controls, particularly in the PND males since the body-weight differences were less between groups among the males. Female animals did not show this feature and this may be the result of slower growth recovery seen in females. It is therefore not possible to attribute to the PND rats a change in metabolic efficiency as part of the adaptive response to energy restriction early in life. However, as suggested by Mohan \& Narasinga Rao (1983), it is possible that a feature of adaptation of young growing rats to low-energy intake may be a reduction in tissue deposition of fat and a better utilization of energy for maintenance without reducing the RMR.

The NST capacity of the PND rats at weaning was reduced by $50 \%$ compared with that of the controls. The differences in NST capacity persisted even when corrected for body-weight. This reduction in NST capacity is possibly an adaptive response since NST is now recognized as playing a central role in the regulation of energy balance in man as well as animals (Trayhurn \& James, 1981). This depressed capacity for NST in PND rats is compensated for by the lower body temperature of these animals which may help to offset this deficiency by reducing energy expenditure on thermoregulatory thermogenesis. The restoration of NST capacity of PND rats to levels comparable to those of controls was rapid following adequate nutritional rehabilitation and indicates that the increase in energy input increases energy expenditure to comparable levels. This is in keeping with the concept that both dietary-induced thermogenesis and NST are mutually exclusive and are both mediated through the sympathetic nervous system (Rothwell \& Stock, 1980). Unlike changes in core temperature which persist even after nutritional rehabilitation, the reduction in NST capacity, largely mediated through sympathetic responsiveness of tissues, appears to be reversible. The absolute NST capacity $(\mathrm{ml} / \mathrm{h}$ per animal) seemed to be comparable with that of the controls in the case of males, while the NST capacity of females continued to remain low. This important residual difference between the NST capacity of the sexes may be related to differences in the metabolic efficiency of females (Hoyenga \& Hoyenga, 1982) who are subject to alterations in responsiveness to noradrenaline during pregnancy and lactation (Trayhurn et al. 1982; Trayhurn, 1983).

The major function of CIT in rats and other mammals is to promote survival during cold stress by augmenting heat production (Jansky, 1973). At weaning, the PND animals were unable to thermoregulate on cold exposure $\left(5^{\circ}\right)$ and died while controls, despite a drop in core temperature, survived similar cold exposure for $2 \mathrm{~h}$. A transient defect in CIT was seen in the PND rats during cold exposure even at 4 weeks of age. The rapid recovery in thermoregulatory thermogenesis possibly reflects limited availability of substrates to sustain thermogenesis and the fact that other mechanisms, such as shivering or reduction in heat loss, may play an important role during cold exposure, thus helping the animal to survive. Following nutritional rehabilitation the small discrepancy in CIT completely disappeared, indicating that there was no compromise in thermal regulation of these animals.

It would thus appear that the morphological changes, particularly the reduction in body size and composition, determine the changes seen in resting $\mathrm{O}_{2}$ consumption of rats nutritionally deprived early in life. Adaptive changes in NST are limited to the period of restriction and do not appear to confer any increased metabolic efficiency to these animals. They may therefore possibly be related to a lowered sympathetic drive or to limited availability of substrates and may not be a consequence of changes in brown adipose tissue 
function. The transient decrease in NST, however, compromises the body's reponse to cold exposure which recovers, with recovery in NST capacity very quickly following rehabilitation.

The authors wish to thank Mr K. Shivaiah for technical assistance. P.S.S. acknowledges a grant-in-aid of equipment from the Wellcome Trust. D.V.M. was in receipt of an Indian Council of Medical Research Senior Research Fellowship.

\section{REFERENCES}

Apfelbaum, M. (1978). Progress in Food and Nutrition Science 2, 543-559.

Ashworth, A. (1969). Nature 223, 407-409.

Brenton, D. P., Brown, R. E. \& Wharton, B. A. (1967). Lancet i, 410-413.

Davis, T. R. A. \& Mayer, J. (1954). American Journal of Physiology 177, 222-226.

Dorner, G. (1974). Acta Biologica et Medica Germanica 33, 129-148.

Forsum, E., Hillman, P. E. \& Nesheim, M. C. (1981). Journal of Nutrition 111, 1691-1697.

Grande, F. (1964). In Handbook of Physiology. Sect. 4, pp. 911-937 [D. B. Dill, editor]. Washington, D.C.: American Physiological Society.

Hoyenga, K. B. \& Hoyenga, K. T. (1982). Physiology and Behaviour 28, 545-563.

Jansky, L. (1973). Biological Reviews of the Cambridge Philosophical Society 48, 85-132.

Khan, M. A. \& Bender, A. E. (1979). Nutrition and Metabolism 23, 449-457.

Kibler, H. H. \& Brody, S. (1942). Journal of Nutrition 24, 461-468.

Kleiber, M. (1947). Physiological Reviews 27, 511-541.

McCance, R. A. (1976). In Early Nutrition and Later Development, pp. 149-155 [A. W. Wilkinson, editor]. London: Pitman Medical Publishing Co.

McCance, R. A. \& Mount, L. E. (1960). British Journal of Nutrition 14, 509-518.

Mitchell, H. H. (1962). In Comparative Nutrition of Man and Domestic Animals, vol. 1, pp. 3-90. New York: Academic Press.

Mohan, P. F. \& Narasinga Rao, B. S. (1983). Journal of Nutrition 113, 79-85.

Muralidhara, D. V. \& Shetty, P. S. (1983). Indian Journal of Physiology and Pharmacology 27, 345-349.

Rothwell, N. J. \& Stock, M. J. (1980). Canadian Journal of Physiology and Pharmacology 58, 842-848.

Shetty, P. S., Jung, R. J. \& James, W. P. T. (1979). Lancet i, 77-79.

Trayhurn, P. (1979). Pfiügers Archiv 380, 227-232.

Trayhurn, P. (1983). Pflügers Archiv 398, 264-265.

Trayhurn, P., Douglas, J. B. \& McGuckin, M. M. (1982). Nature 298, 59-60.

Trayhurn, P. \& James, W. P. T. (1978). Pflügers Archiv 373, 189-193.

Trayhum, P. \& James, W. P. T. (1981). In The Body Weight Regulatory System: Normal and Disturbed Mechanisms, pp. 97-105 [A. L. Cioff., W. P. T. James and T. B. Van Itallie, editors]. New York: Raven Press.

Viteri, F. E. \& Tonun, B. (1980). IN Modern Nutrition in Health and Disease, pp. 697-720 [R. S. Goodhard, and M. F. Shills, editors]. Philadelphia: L and F.

Widdowson, E. M. \& McCance, R. A. (1960). Proceedings of the Royal Society, Series B, 152, 188-206.

Wurtman, J. J. \& Miller, S. A. (1976). Journal of Nutrition 106, 697-701. 